\title{
CAPITAL Y NEGOCIOS: EL COMERCIO AGREMIADO DE MADRID A FINALES DEL SIGLO XVIII.
}

por

\author{
Juan Carlos Sola Corbacho \\ Universidad Complutense de Madrid
}

RESUMEN: A finales del siglo XVIII el sector comercial agrupado en tomo a los Cinco Gremios Mayores de Madrid era el más importante en España. La bistoriografia, sin embargo, apenas ba prestado atención a la dinámica que impulsaban sus integrantes si no ba sido para subrayar las escasas repercusiones que tuwo para la economía de la ciudad y de la región en donde ésta se localizaba. La mayoria de quienes ban llegado a tales conclusiones ban realizado sus juicios a partir fundamentalmente de las afirmaciones realizadas por los contemporáneos o, sencillamente, teniendo en cuenta únicamente las iniciativas desarmolladar a nivel institucional. Sin embargo, a travér de los inventarios que realizaron en los que registranon todos los bienes que formaban parte de sus negocios queda claro que sus participaciones en la corporación tan sólo representaban una minima parte del valor de sus etablecimientos. Es más, la mayor parte del capital con el que negocianon a sravés de las instituciones corporativas fue invertido en el sector comerial y manufacturero peninsular. Ante tales becbos, bay que volver a preguntarse por qué no fueron capaces de introducir cambios en la organización económica española y más concretamente en la del interior peninsular.

Palabras Clave: Siglo XVIII. España. Madrid. Economía. Cinco Gremios Mayores de Madrid. Reformismo Ilustrado. Capital. Negocios. Compañías de Comercio. Actividades comerciales. Manufacturas.

ABSTRACT: At the end of the eighteenth century, the commercial sector which had founded the Cinco Gremios Mayores de Madrid was the most important in Spain. Researchers, nevertbeless, bave not pay attention to the activities of its members except to underline the minor impact they bad on the city and regional economies. Most of their studies are based on assessments made by contemporaries and on the characteristics of the activities carried out by this institution. Nevertheless, the study of the invencories made by these merchants reveals that their investments in the Cinco Gremios

Hispania, LX/1, núm. 204 (2000) 225-253 


\begin{abstract}
Mayores involved only a small part of their capital. Moreover, most of this capital was invested by the managament of this institution in the Spanish commercial and industrial sectors. Under these circumstances, it is necessary to ask again wby the commercial sector from Madrid was not able to introduce new factors tbat may bave changed the economic systems of Spain in general and Castilla in particular.
\end{abstract}

KEY WORDS: Eighteenth Century. Spain. Madrid. Economy. Cinco Gremios Mayores de Madrid. Enlightened Reforms. Capital. Business. Trade Companies. Commercial activity. Manufacture.

Tradicionalmente la historiografía ha definido a la burguesia mercantil española del siglo XVIII como un sector social incapaz de generar cambios en el sistema económico en el que desarrollaban sus actividades. Tal caracterización, de la que sólo se excluye a quienes se asentaban en territorio catalán, incluía la generalización de ciertas actitudes al resto de los que negociaban en otras plazas peninsulares, adquiriendo sus aspectos más dramáticos en el caso de quienes lo hacían en los principales centros urbanos castellanos. Entre ellas destacan: la debilidad financiera de sus negocios, su escasa vinculación a la dinámica del sector manufacturero, su estrecha relación con el comercio exterior y la propiedad agraria o su incapacidad para fomentar desde los centros urbanos la articulación de los mercados regionales. Además, en relación a sus formas de vida, se ha subrayado que su máxima aspiración era vivir noblemente, casar con hidalgas, adquirir un título, abandonar el comercio y, al cabo de algunas generaciones, hacer que se olvidase el origen de su fortuna.

Afortunadamente la perspectiva regional que se ha venido imponiendo en el desarrollo de los estudios históricos durante los últimos años ha incluido análisis más pormenorizados de las actividades y el ordenamiento interno del sector social al que nos venimos refiriendo. Esto ha hecho que se hayan empezado a cuestionar algunas de las afirmaciones anteriormente señaladas o al menos matizar el afán generalizador que en este sentido dominaba. Sin embargo, tal perspectiva no ha supuesto modificación alguna en el interés existente por profundizar en el conocimiento del comercio madrileño, y ello a pesar de que económicamente era el más poderoso en la España de finales del siglo XVIIl'. De hecho, sigue prevaleciendo la idea de su carácter tradicional fundamentada en que en su ordenamiento interno predominaba la estructura corporativa de los Cinco Gremios Mayores. A tales argumentos se ha unido además la aceptación de que entre los integrantes del mencionado sector prevalecían las actividades relacionadas básicamente con el consumo suntuario de la nobleza cortesana, el

\footnotetext{
1 Es significativo que la monografía más completa acerca del comercio agremiado madrileño siga siendo CAPELLA y MATILLA TASCÓN (1957). Por su parte, RuNGROSE (1985) apenas aporta nada nuevo sobre su organización o actividades.
}

Huspania, LX/1, núm. 204 (2000) 225-253 
abastecimiento de los productos básicos demandados en la ciudad o con los asientos acordados con la Corona. Todo ello, en definitiva, ha servido para justificar, como ya hemos señalado, que la dinámica del sector mercantil de la ciudad apenas llegara a influir, si no fue de manera negativa, sobre la del sistema económico castellano y peninsular en general.

Ahora bien, es necesario ser prudente a la hora de aceptar tales afirmaciones. De hecho, hay que empezar por cuestionar el hecho de que se identifique el carácter rígidamente corporativista de los agremiados con el conservadurismo asociado a la mentalidad del colectivo y con la orientación dada a sus inversiones, sobre todo si tenemos presente que tales estructuras eran las mismas que se imponían en estas fechas en el sector mercantil de Barcelona ${ }^{2}$. Peto, además, es necesario insistir en que en la mayor parte de los casos las valoraciones realizadas sobre las estrategias a las que nos venimos refiriendo cuando no se han basado en las declaraciones partidistas de los contemporáneos, notablemente negativas en el caso de los primeros liberales que como Larruga destacaron en el último tercio del siglo ${ }^{3}$, lo han hecho en la dinámica que caracterizaba a las instituciones corporativas sin saber hasta qué punto tales actividades deben ser consideradas como la única referencia a tener en cuenta a la hora de definir la de los negocios mercantiles de la ciudad, pues si algunos de sus propietarios no estaban integrados en la corporación, no sabemos en qué medida quienes sí lo estaban comprometieron sus capitales en los negocios impulsados en el marco de la mencionada institución ${ }^{4}$.

En este último caso, además, hay que señalar que si la introducción en el ámbito del abastecimiento de la ciudad de bienes básicos o en el de los asientos con la Corona se hizo a través de las instituciones corporativas, éstas no fueron las únicas iniciativas impulsadas en el mencionado marco. De hecho, Capella y Matilla Tascón en su estudio sobre los Cinco Gremios Mayores afirman que desde su definitiva consolidación en el segundo tercio del siglo XVIII sus actividades pueden quedar encuadradas en cinco grupos. Pues bien, además de las de fines fiscales (encabezamiento de los tributos de la Corona y del municipio, arrendamiento de la renta del excusado, administración de las rentas reales, etc), de las de carácter financiero o bancario (giro de letras o apertura de líneas de descuento) o de las que dichos autores definen como actividades varias (seguros a la navegación por mar, fletamento de buques), Capella y Matilla se refieren a las actividades puramente mercantiles y a los programas de carácter industrial.. Estos últimos incluyen el arrendamiento de las reales fábricas de Talavera, Valencia y Murcia con sus almacenes, de las fábricas de paños de Brihuega, Cuenca y Ezacaray, de la Fábrica de Holandillas, la de sombreros de San Fernando, etc. En

\footnotetext{
2 Ver FERNANDEZ (1982): 1-131

3 Ver LARRUGA, E. (1787): tomo I, memoria IV

4 Según AlmanaK MerCanTIL (1796): 238-250, más del $85 \%$ de quienes se integraban en el sector mercantil madrileño formaban parte de los Cinco Gremios Mayores. El resto, según dicha publicación, eran cambistas, corredores de letras, mayoristas y comerciantes de géneros catalanes.
} 
lo que hace a las mercantiles afirman que estaban orientadas, por una parte, a la defensa de los privilegios comerciales de sus integrantes en el interior peninsular y, por otra, al desarrollo de intercambios entre la metrópoli y las colonias, así como con otras economías de Europa y del Norte de Áfricas.

En definitiva, a pesar de que ha venido existiendo una coincidencia general a la hora de caracterizar al sector mercantil madrileño a finales del siglo XVIII, no parece que las valoraciones realizadas se hayan derivado de la elaboración de estudios pormenorizados del mismo. Es por eso por lo que a lo largo de las siguientes páginas nos proponemos realizar un análisis sobre el comercio agremiado de la capital imperial en el último tercio de la centuria, atendiendo especialmente a la estructura de sus negocios y a las estrategias inversionistas que determinaron la dinámica del mencionado sector.

\section{INVERSIÓN, ESTRUCTURA Y BENEFICIOS DE LOS ESTABLECIMIENTOS MER- CANTILES}

En el empeño por definir la dinámica económica de las casas de comercio de la ciudad y, más concretamente, la capitalización de las mismas, nos hemos basado en la información contenida en documentación de naturaleza notarial. Especialmente en los inventarios que sus administradores o propietarios elaboraron registrando todo lo que formaba parte del negocio. Tales escrituras solían ser protocolizadas en momentos por los que prácticamente todos los agremiados pasaban a lo largo de su carrera en la ciudad y que además marcaban para la mayor parte de ellos el transcurrir de su trayectoria en el sector mercantil de la capital imperial: la asociación con otro comerciante, la compra de un establecimiento, el matrimonio o la muerte.

En total, como se puede apreciar en el cuadro 1, hemos podido encontrar el valor de más de un centenar y medio de establecimientos propiedad de algún agremiado según los correspondientes documentos fechados en el último tercio del siglo XVIII. Las dos terceras partes de dichos negocios estaban valorados por debajo de los trescientos mil reales. Algo más de la cuarta parte financiaban sus actividades con un caudal superior a los trescientos mil e inferior al millón de reales, mientras que tan sólo uno de cada diez sobrepasaban esta última cifra.

\footnotetext{
5 Capella y Matilla Tascón (1957): 269-287
} 
CUADRO 1. Estructura del comercio agremiado de Madrid en función del valor de los negocios, $1765-1800$

\begin{tabular}{|l|c|c|}
\hline $\begin{array}{l}\text { VALOR DE LOS NEGOCIOS } \\
\text { (reales) }\end{array}$ & $\begin{array}{l}\text { NÚMERO DE NEGOCIOS } \\
\text { (Total) }\end{array}$ & $\begin{array}{l}\text { PORCENTAJE SOBRE } \\
\text { LOS NEGOCIOS } \\
\text { CONTABILIZADOS }\end{array}$ \\
\hline Hasta 100.000 & 51 & $30^{\dagger} 7$ \\
\hline Entre 100.001 y 300.000 & 52 & $31^{\prime} 3$ \\
\hline Entre 300.001 y 500.000 & 18 & $10^{\prime} 9$ \\
\hline Entre 500.001 y 700.000 & 17 & $10^{\prime} 3$ \\
\hline Entre 700.001 y 1.000 .000 & 12 & $7^{\prime} 2$ \\
\hline Más de 1.000 .000 & 16 & $9^{\prime} 6$ \\
\hline Total & 166 & $100^{\prime} 0$ \\
\hline
\end{tabular}

Fuente: Archivo Histórico de Protocolos de Madrid (A.H.P.M.)

Hemos podido ser un poco más concretos y, como se puede apreciar en los cuadros 2 y 3 , hemos agrupado las cifras obtenidas en función de los gremios en los que se inscribían los dueños de los negocios. Los contenidos de dichos cuadros reflejan las diferencias existentes en el interior del propio sector. En este sentido habría que destacar la capitalización de los establecimientos administrados por los comerciantes integrados en el gremio de sedas. Entre ellos uno de cada tres de los que hemos registrado superaba el millón de reales, prácticamente el mismo porcentaje de los que no pasaban de los trescientos mil reales. De la misma manera, es relevante el escaso volumen de capital con el que negociaban los comerciantes del gremio de joyería y el de los que lo hacían integrados en el de droguería, especiería y mercería. En relación al primero de los dos casos hay que reseñar que el $90 \%$ de los establecimientos quedaron valorados por debajo de los trescientos mil reales, mientras que en lo que hace al segundo, no hemos podido encontrar negocio alguno que superara el millón de reales.

Sin embargo, algunas de las cifras que acabamos de apuntar quedan a cierta distancia de las que incluía Larruga en su obra Memorias políticas y económicas sobre los frutos, comercio, fábricas y minas de España.. Las diferencias son casi inapreciables en lo que hace al valor medio que hemos calculado para los negocios administrados por los comerciantes agremiados de la ciudad, pues si de la información recopilada por el mencionado autor se desprende que el mismo ascendería a 562.082 reales, de la que se deriva de la muestra que hemos presentado con anterioridad, éste quedaría en 548.423 reales. Más notables son, sin embargo, con respecto a lo que hemos señalado sobre el capital con el que negociaban los miembros de los gremios de droguería, especiería y mercería, y

Hispania, IX/1, núm. 204 (2000) 225-253 
CUADRO 2. Estructura del comercio agremiado de Madrid en función del valor de los negocios, 1765-1800 (por gremios)

\begin{tabular}{|l|c|c|c|c|c|c|}
\hline $\begin{array}{l}\text { VALOR DE LOS } \\
\text { NEGOCIOS } \\
\text { (en reales) }\end{array}$ & $\begin{array}{c}\text { LIENZOS } \\
(\%)\end{array}$ & $\begin{array}{c}\text { PAŃOS } \\
(\%)\end{array}$ & $\begin{array}{c}\text { SEDAS } \\
(\%)\end{array}$ & $\begin{array}{c}\text { JOYERIA } \\
(\%)\end{array}$ & $\begin{array}{c}\text { DROGUERí, } \\
\text { ESPECIERIA Y } \\
\text { MERCERí (\%) }\end{array}$ & $\begin{array}{l}\text { MEDIA } \\
\text { GREMIAL (\%) }\end{array}$ \\
\hline Hasta 100.000 & $33^{\prime} 3$ & $15^{\prime} 8$ & $12^{\prime} 5$ & $51^{\prime} 6$ & $34^{\prime} 8$ & $30^{\prime} 7$ \\
\hline $\begin{array}{l}\text { Entre } 100.001 \text { y } \\
300.000\end{array}$ & $24^{\prime} 2$ & $36^{\prime} 5$ & $25^{\prime} 0$ & $38^{\prime} 7$ & $27^{\prime} 9$ & $31^{\prime} 3$ \\
\hline $\begin{array}{l}\text { Entre 300.001 y } \\
\text { 500.000 }\end{array}$ & $9^{\prime} 1$ & $18^{\prime} 4$ & $16^{\prime} 7$ & $3^{\prime} 2$ & $14^{\prime} 0$ & $10^{\prime} 9$ \\
\hline $\begin{array}{l}\text { Entre } 500.001 \text { y } \\
700.000\end{array}$ & $15^{\prime} 2$ & $18^{\prime} 4$ & $4^{\prime} 1$ & $0^{\prime} 0$ & $9^{\prime} 3$ & $10^{\prime} 3$ \\
\hline $\begin{array}{l}\text { Entre 700.001 y } \\
1.000 .000\end{array}$ & $6^{\prime} 1$ & $2^{\prime} 6$ & $12^{\prime} 5$ & $0^{\prime} 0$ & $14^{\prime} 0$ & $7^{\prime} 2$ \\
\hline $\begin{array}{l}\text { Más de } \\
1.000 .001\end{array}$ & $12^{\prime} 1$ & $7^{\prime} 9$ & $29^{\prime} 2$ & $6^{\prime} 5$ & $0^{\prime} 0$ & $9^{\prime} 6$ \\
\hline
\end{tabular}

El número de negocios que integran la muestra de cada uno de los gremios es respectivamente de $33,38,24,31$ y 43 .

Fuentes: Archivo Histórico de Protocolos de Madrid (A.H.P.M.).

CUADRO 3. Estimación del capital con el que operaba el sector agremiado del comercio madrileño a finales del siglo XVIII

\begin{tabular}{|l|c|c|c|}
\hline GREMIOS & $\begin{array}{l}\text { VALOR BRUTO } \\
\text { TOTAL. GREMIO } \\
\text { (miles de reales) }\end{array}$ & $\begin{array}{l}\text { VALOR NETO } \\
\text { TOTAL. GREMIO } \\
\text { (miles de reales) }\end{array}$ & $\begin{array}{l}\text { VALOR NETO POR } \\
\text { NEGOCIO (reales) }\end{array}$ \\
\hline LIENZOS & 53.246 & 46.381 & 498.721 \\
\hline PAÑOS & 31.374 & 26.921 & 480.747 \\
\hline SEDAS & 46.736 & 44.702 & 1.241 .745 \\
\hline JOYERÍA & 17.801 & 15.646 & 256.500 \\
\hline DROGUERIA & 28.125 & 24.589 & 264.402 \\
\hline TOTAL & 177.283 & 158.306 & 548.423 \\
\hline
\end{tabular}

Fuentes: Archivo Histórico de Protocolos de Madrid (A.H.P.M.)

los que lo hacían integrados en el de joyería y sedas. Según los datos incluidos en la obra a la que venimos refiriéndonos, si los establecimientos administrados por los miembros de la corporación giraban con un capital total de doscientos diez millones de reales, en su distribución primaba la importancia del gremio

Hispania, LX/1, núm. 204 (2000) 225-253 
de droguería, especiería y mercería al que asignaba 90 millones de reales, seguido por el de lienzos (cuarenta millones), sedas (veintiocho millones), y paños y joyería (con veintiséis millones de reales en ambos casos) ${ }^{6}$. De ello se deduce que el negocio del agremiado de droguería, especiería y mercería alcanzaría un valor medio de 697.674 teales (el que hemos dado nosotros es de 264.402 reales), el del agremiado de joyería sería de 426.229 (mientras que el que le hemos conferido nosotros es de 256.500 reales) y el de sedas de 777.777 reales (frente a 1.241 .745 reales que hemos asignado). Según tales cálculos, el ordenamiento que según el volumen de capital invertido en los negocios caracterizaría al gremio de droguería, especiería y mercería, sería similar al que nosotros hemos propuesto para el gremio de sedas, mientras que el de joyería debía ser parecido al que hemos visto para los de lienzos o paños (ver cuadros 2 y 3 ).

En cualquier caso y a pesar de tales diferencias, la estructura del comercio agremiado madrileño seguiría las mismas pautas antes apuntadas, es decir, un grupo mayoritario (alrededor del 50\% del total siguiendo a Larruga, en torno al $60 \%$ según nuestros cálculos) cuyos negocios no sobrepasarían los trescientos mil reales. Otro algo más reducido, entre aproximadamente la tercera parte, a partir de los datos de Larruga, y la cuarta parte del total, según los nuestros, cuyos establecimientos estarían valorados entre los trescientos mil y el millón de reales. Y, por último, una minoría que, según la información del mencionado autor, se situaría alrededor del $17 \%$ (10\% si tuviéramos en cuenta las fuentes que han servido de base a este estudio), cuyos comercios contarían con un capital superior al millón de reales'.

Respecto a la definición de cada una de las partidas que componían el volumen de capital invertido en los establecimientos y la proporción que sobre el mismo suponían, como se puede ver en el cuadro 4, hay que destacar que cuanto mayor era el capital invertido en el negocio más repartido se encontraba éste, incrementándose el valor de la deuda pública, en la que hemos incluido desde vales reales a obligaciones de la administración municipa ${ }^{8}$, el dinero en efectivo ${ }^{9}$ y la inmovilización de parte de sus bienes al emplearlos en la contra-

\footnotetext{
6 LARRUGa (1787): Tomo I, Memoria I p. 20-21 y Tomo I, Memoria V, p. 248

7 La estructura del sector que hemos basado en las cifras aportadas por Larruga se ha perfilado teniendo presences los datos obrenidos en la documentación notarial, relacionando el valor medio de los negocios con el ordenamienco de cada uno de los gremios.

${ }^{8}$ La tercera parze de los negocios valorados en más de 300.000 reales y menos de un millón tenian registrado como parte de su capital detuda pública. La proporción que ésta suponía sobre el caudal de los mismos asciende al 20,8\%. La media para todo el grupo es del $8,4 \%$. Entre los negocios más importantes el valor medio llegaba a ser de $9,1 \%$, siendo que dos de cada tres comerciantes las registraban. En estos establecimientos tales inversiones representaban el 15,3\% del caudal contabilizado.

9 Tan sólo uno de cada cinco de los agremiados propietarios de los negocios de menor caudal declaraban tener como parte de los bienes de la tienda dinero en metálico. La media del efectivo en estos negocios llegaba a ser del $14,6 \%$ del total. $\mathrm{Al}$ igual que entre los más ricos agremiados, tres de cada cuatro de los comerciantes que poseían un establecimiento valorado entre trescientos mil y un millón de reales registraban esta partida. Esta suponía en los casos en los que se registraba entre el
} 
tación de depósitos a plazos e intereses fijos con diferentes instituciones madrileñas, incluidas las de los Cinco Gremios Mayores ${ }^{10}$, a costa fundamentalmente de las mercadurías y de las acciones y participaciones en la corporación ${ }^{11}$.

CUADRO 4. Estructura de los negocios de los comerciantes madrileños a finales del siglo xviii (porcentajes).

\begin{tabular}{|l|c|c|c|c|c|c|}
\hline $\begin{array}{l}\text { VOLUMEN } \\
\text { DE CAPITAL } \\
\text { INVERTIDO } \\
\text { EN LOS } \\
\text { NEGOCIOS } \\
\text { (en reales) }\end{array}$ & MERCANCfAS & $\begin{array}{l}\text { DEUDAS } \\
\text { A FAVOR }\end{array}$ & $\begin{array}{l}\text { ACCIONES Y } \\
\text { PARTICIPA- } \\
\text { CIONES EN LA } \\
\text { CORPORA- } \\
\text { CIÓN }\end{array}$ & EFECTIVO & OTROS & TOTAL \\
\hline $\begin{array}{l}\text { Menos de } \\
300.000\end{array}$ & $56^{\prime} 8$ & $21^{\prime} 6$ & $16^{\prime} 4$ & $3^{\prime} 8$ & $1^{\prime} 4$ & $100^{\prime} 0$ \\
\hline $\begin{array}{l}\text { Entre 300.001 } \\
\text { y 1.000.000 }\end{array}$ & $33^{\prime} 2$ & $32^{\prime} 4$ & $15^{\prime} 8$ & $4^{\prime} 3$ & $14^{\prime} 3$ & $100^{\prime} 0$ \\
\hline $\begin{array}{l}\text { Más de } \\
1.000 .000\end{array}$ & $28^{\prime} 0$ & $34^{\prime} 6$ & $10^{\prime} 3$ & $9^{\prime} 4$ & $17^{\prime} 7$ & $100^{\prime} 0$ \\
\hline $\begin{array}{l}\text { Media de los } \\
\text { tres grupos }\end{array}$ & $39^{\prime} 4$ & $29^{\prime} 5$ & $14^{\prime} 2$ & $5^{\prime} 8$ & $11^{\prime} 1$ & $100^{\prime} 0$ \\
\hline
\end{tabular}

(*) En Otros se incluye fundamentalmente lo que suponia la contratación de depósitos, la deuda pública, la anaquelería de la tienda y, en mucha menor medida acciones de la Compañía de Filipinas o participaciones en compañías de seguros marícimos.

Fuentes: Archivo Histórico de Protocolos de Madrid (A.H.P.M.)

$5,7 \%$ de lo invertido en el establecimiento, para el segundo de los dos grupos, y el I 1,8\% para los almacenes de mayor valor.

10 Entre los negocios valorados entre 300.000 y 1.000 .000 de reales tales inversiones suponían como media el 2,1\% del caudal y entre la décima parte de ellos que las registraban el 22,8\%. Hay que señalar además que los pocos que confesaban tener parte de su capital invertido en la contratación de depósitos a interés hacían lo propio con deuda pública, siendo que ambas partidas llegaban a totalizar entre la décima parte y la mitad del valor de sus casas de comercio. Entre los más ricos la media alcanzada es del $5,3 \%$, y para cada uno de los seis agremiados que decidieron negociar parte de su caudal de esta forma el $32 \%$ del capical invertido en el establecimiento. La gran mayoría de los agremiados que negociaron con esce tipo de depósitos también eran acreedores de la administración pública. En conjunto, la suma de ambas en estas ocasiones llegaba a representar la mitad del valor tozal del negocio

11 A pesar de que las reglamentaciones gremiales les obligaban a emplear parze de su capital en la compra de acciones de la Compañia General de Comercio de los Cinco Gremios Mayores o de cualquiera de las compañías fundadas por alguno de los gremios de manera individual, sólo la mitad de los agremiados propietarios de los negocios de menor valor las incluían como parte de sus bienes. Si tan sólo contabilizáramos estos casos, tales inversiones supondrían por término medio el 36,6\% del caudal de los negocios. 'Tres de cada cuatro de los propietarios de los establecimientos que hemos incluido en el segundo grupo declaraban tener acciones. La media de lo que invirtieron era del $20,1 \%$ y para el grupo en conjunto del $15,8 \%$. Entre los admacenes más importantes tal índice descendía al 10,3\%; el $14,7 \%$ si contabilizamos únicamente los inventarios en los que se registra su posesión.

Hispania, LX/1, núm. 204 (2000) 225-253 
En cualquier caso, teniendo presente el escaso volumen de capital destinado a ser invertido fuera del ámbito comercial, al menos en relación con el valor de las mercadurías o con el de sus negocios en general, se puede afirmar que la tendencia a la que nos venimos refiriendo ha de ser interpretada más que como un progresivo abandono de las actividades mercantiles, como un intento por diversificar los riesgos aparejados al incremento de las operaciones comerciales en el interior peninsular del que la capital imperial formaba parte, en donde en general predominaba la inestabilidad de la demanda, la escasez de circulante, las oscilaciones cíclicas características de las economías de base agraria o el ritmo anual de los ingresos derivados de las rentas rústicas. No es, pues, extraño que ni las deudas a favor fuera la partida de mayor importancia en el activo de los principales establecimientos madrileños a finales del siglo, ni que el dinero en metálico contabilizado fuera notablemente escaso. Además, en tales circunstancias, la inexistencia de recargos o intereses sobre las cantidades adeudadas y la más que probable pérdida de valor que sufrían los correspondientes compromisos de pago con el paso del tiempo no sólo condicionaba una inmovilización forzada del capital implicado, sino también la propia viabilidad de los negocios en general y no sólo los de menor capacidad. Por último, otro de los graves inconvenientes que debieron afrontar las casas comerciales madrileñas es la situación financiera por la que atravesó la Corona en los últimos años de la centuria, como lo demuestra el hecho de que, sobre todo entre los más importantes comerciantes de la ciudad, la posesión de vales reales no sólo formaba parte esencial de sus negocios, sino también un lastre esencial para los mismos.

Los propietarios de los negocios de menor valor de la ciudad encontraton en su incorporación a la organización gremial una de las claves para dotar de suficiente estabilidad económica a sus establecimientos, siendo para otros factor determinante de los progresos que realizaron a lo largo de su carrera. Uno de los aspectos más importantes en esta relación entre el agremiado y la corporación, especialmente para aquellos que administraban establecimientos con un volumen de capitalización no muy elevado, era la participación en las actividades económicas emprendidas por la institución mediante la adquisición de acciones de las compañías creadas en el seno de cada uno de los gremios, ya fuera, como veremos más adelante, las que se dedicaron al comercio o las que nacieron con la idea de explotar un centro de producción manufactureto, o bien, aunque en menor grado, de la posesión de intereses relacionados con las operaciones desarrolladas por la Diputación de los Cinco Gremios Mayores.

A partir de la información contenida en las escrituras que hemos podido encontrar en las que se especificaban los beneficios obtenidos por los comerciantes agremiados en su condición de accionistas o de interesados de las actividades de la Diputación de los Cinco Gremios Mayores de Madrid o de las compañías de comercio de dicha corporación hemos podido deducir que tales utilidades pudieron oscilar entre algo más de tres mil reales y casi veinticinco mil reales anuales, o lo que es lo mismo entre el $65 \%$ y el $30 \%$ anual sobre el 
capital invertido ${ }^{12}$. Tales cifras son muy elevadas no sólo en relación a lo que percibían los inversionistas de otras compañías españolas de similares características ${ }^{13}$, sino también en comparación con lo que los miembros de la corporación ingresaban por otros conceptos. Por ejemplo, en algunas escrituras los agremiados madrileños incluyeron el cálculo de lo que ingresarían o de lo que habían obtenido por la venta de mercadurías en sus establecimientos. En las que hemos encontrado tales cantidades oscilan entre los tres mil y los doscientos cincuenta mil reales anuales, siendo que la mayor parte de los negocios sobrepasaba los veinte mil reales anuales, mientras que la media se situaba por encima de los sesenta y un mil reales anuales. Las dos terceras partes no obtenían como producto de tales actividades más del $5 \%$ de lo que habían invertido, siendo que el mínimo registrado era del $1^{\prime} 1 \%$, el máximo el $48 \%$ y la media del $9 \%{ }^{14}$.

Todo ello, pues, permite pensar en que con cierta frecuencia los beneficios acumulados en su calidad de accionistas de las compañías gremiales fueran superiores, sobre todo en los establecimientos de menor capitalización, a las cantidades que obtenían de la comercialización de los géneros que ofertaban en sus establecimientos ${ }^{15} \mathrm{y}$, entre los más ricos comerciantes, a las que se derivaron de sus intereses en los negocios emprendidos de manera institucional, fundamentalmente los de la Diputación e incluso a los que conseguían mediante la movilización de las mercadurías en el ámbito del comercio atlántico.

Esto último queda claramente reflejado en la liquidación del haber que le correspondió a José de Entrambasguas tras su separación de la compañía que

12 Ver, por ejemplo, Archivo de Protocolos de Madrid (A.H.P.M.) Protocolo (Prot): 19638; folio (fol): 91; fecha: 6/7/81. Prot: 20879; fecha: 21/3/69. Prot: 20879; fecha: 19/7/69. Prot: 18809; fol: 139; fecha: 10/2/76. Prot: 19967; fol: 29; fecha: 20/1/78. Prot. 19967; fol: 120, fecha: 30/3/78. Prot. 20563; fol: 11/4/95; Prot. 20563; fol: 441; fecha: 24/2/95. Proc: 20563; fol: 303; fecha: 11/4/95. Prot: 19811; fol: 327; fecha: 11/6/88; Prot: 18953; fol: 26; fecha: $13 / 3 / 73$

13 Según VILAR (1978): 431 y 445-446, la Compañía de Comercio de Barcelona repartió beneficios equivalentes al $20 \%$ del capital en 1771 , siendo del $12 \%$ en 1777 . Este mismo auror afirma que a finales de siglo una gran sociedad de seguros marítimos barcelonesa no garantizaba a sus accioniscas más del $6 \%$ de ganancias.

14 Ver, por ejemplo, A.H.P.M. Prot. 22636; fol: 454; fecha: 14/10/96. Prot. 21479; fecha: 7/2/94. Prot: 20487; fol: 355; fecha: 23/6/73. Prot. 21479; fecha: 7/2/94. Prot: 19978; fol: 293; fecha: 4/6/92. Prot: 19645; fol: 191; fecha: 15/12/98. Prot: 19643; fol: 47; fecha: 15/2/93. Prot: 19643; fol: 1; fecha: 2/1/93. Prot: 19979; fol: 1; fecha: 2/1/93. Prot. 19978; fol: 162; fecha: 6/4/92. Prot. 19641; fol: 117; fecha: 13/6/89. Prot. 20395; folio: 340; fecha: 23/7/68. Prot. 22329; fol: 161; fecha: 14/11/94.

1s Si entre el grupo de comerciantes que operaban con un caudal inferior a trescientos mil reales, los ingresos logrados mediante la venta de géneros podían suponer un mínimo de algo más del $1 \%$ y un máximo del $10 \%$ del principal de sus negocios, oscilando en la mayor parte de las escrituras en las que éstos se cuantificaban entre los cinco mil y los diez mil reales anuales, siendo que la cantidad máxima que hemos encontrado alcanza los diecisiete mil reales; en to que hace a la rentabilidad de sus participaciones en las operaciones desarrolladas por la corporación gremial, es posible que oscilara entre casi el $7 \%$ y el $30 \%$ del valor de la inversión. 
firmó con Domingo González de Villa. En dicha escritura se incluyen los beneficios obtenidos por este último derivados de sus intereses en la corporación gremial . En total González de Villa percibió 30.603 reales por la participación que tenía en el cabezón de rentas de los Cinco Gremios Mayores entre los años 1780 y 1785 (5.100 reales anuales), 61.491 reales como accionista en la Compañía General de Comercio de los Cinco Gremios Mayores por el período transcurrido entre 1780 y 1785 (10.248 reales anuales) y 98.118 reales al tener títulos de la misma naturaleza en la Compañía del Gremio de Paños por los años 1781 y 1789 (10.902 reales anuales). En total, pues, 190.212 reales producto de su inversión en la corporación (21.134 reales anuales). Sabemos, además, que entre el 1 de enero de 1782 y el 31 de diciembre de 1789 lo que ingresaron como producto del resto de las actividades desarrolladas en la tienda (la venta de mercadurías esencialmente) ascendió a 60.992 reales, es decir, 7.642 reales anuales, la tercera parte de lo contabilizado con respecto a los intereses en las actividades corporativas de los gremios. En febrero de 1795, tras la muerte del mencionado comerciante, sus herederos protocolizaron el inventario de sus bienes, en el que se incluyeron dos acciones en la Compañía del Gremio de Paños que sumaban 116.000 reales, y una tercera en la Compañía General de Comercio de los Cinco Gremios Mayores por un valor de 200.000 reales, mientras que no se hizo referencia al dinero que había introducido en la Diputación. Según tales datos, habria obtenido más del 6'5\% de lo que había depositado en las mencionadas instituciones. Comparado con otros casos parece muy escaso, lo que permite pensar en la posibilidad de que durante el tiempo pasado entre ambas escrituras González de Villa optara por realizar nuevas inversiones en la Corporación ${ }^{16}$.

En cualquier caso, la importancia de estos títulos debió ser muy notable para las viudas o hijas de comerciantes herederas de un negocio. Éstas probablemente estaban convencidas de que tal tipo de inversión no sólo no iba contra el papel que entonces se asociaba a su figura, sino que además tampoco les exigía ni los desvelos ni la experiencia que necesitaba la gestión de un comercio en la capital. De hecho, la herencia de uno de ellos en la ciudad solía imponetles la negociación con una segunda persona para que asumiera la administración del establecimiento, por lo que el volumen de ingresos dependía de la capacidad o habilidad de su socio. Por el contrario, en su condición de accionistas, si por algo debían preocuparse, tampoco en exceso, era por los retrasos en la distribución de los beneficios, lo que, no obstante, quedaba superado por el importante valor que en general se concedía a dichas participaciones. En este sentido, pues, habría que asociar a las acciones gremiales el papel de factor de pervivencia de algunos de los negocios de la ciudad.

16 A.H.P.M. Prot. 20563, fol 303.- fecha 11/4/95. Prot. 20563, fol: 441; fecha: 24/2/95. Prot. 20563, fol 303.- fecha 11/4/95. 
Sin embargo, no eran ni las viudas ni las descendientes de los agremiados las únicas que habian llegado a constatar la potencialidad asociada a las participaciones en los negocios corporativos de los Cinco Gremios Mayores, pues incluso fuera del ámbito de la economía madrileña el interés demostrado hacia dichos títulos era muy notable. De hecho, hemos podido contrastar con cierta frecuencia el establecimiento de compañías entre vecinos de la capital o de fuera de ella con los propios agremiados, por las que al aportar una cantidad de dinero en metálico equivalente a la mitad de su valor compartían las utilidades derivadas de las acciones ${ }^{17}$. En algunas ocasiones tales asociaciones se convirtieron, ante la escasez de recursos del aspirante y las condiciones que establecía la corporación para ingresar en ella, en la única vía para conseguir la incorporación a alguno de los gremios y la apertura de un establecimiento propio ${ }^{18}$.

Estos acuerdos, por tanto, significaban para quienes habían adquirido la experiencia pero no el capital suficiente la posibilidad de incorporarse al sector, mientras que a quienes ya formaban parte de él les facilitaba el acceso a una nueva fuente de financiación fuera del ámbito mercantil en condiciones óptimas. En este segundo caso tanto como en los anteriores, el socio que no desarrollaba actividades comerciales encontraba un medio bastante seguro para rentabilizar su dinero. De hecho, hay que subrayar que en estas ocasiones estos últimos optaban por invertir aceptando los riesgos aparejados a las actividades de la corporación correspondiente en lugar de hacerlo con respecto al resto de las que desarrollaban de manera individual los agremiados, lo que demuestra claramente la confianza que transmitían entonces las instituciones gremiales. En general, pues, se puede afirmar que tales fórmulas de participación se definían como una vía más de canalización de capital hacia el ámbito comercial de la ciudad.

Ahora bien, la importancia que tenía la institución para la dinámica de los negocios de este sector del comercio madrileño no se reduce a lo que acabamos de exponer. De hecho, en su condición de agremiado, las relaciones del comerciante con las compañías creadas en el seno de la corporación eran de gran trascendencia, ya que podían acudir a sus almacenes, como a los de cualquier otro mayorista, para abastecer sus establecimientos de las mercadurías con las que las reglamentaciones les permitía comerciar, pero sobre todo porque podían hacerlo en unas condiciones privilegiadas en función de su carácter de miembro de los Cinco Gremios Mayores.

Esto último queda perfectamente reflejado en la forma en la que Antonio Fernández Manín negoció la satisfacción de los 180.372 reales que adeudaba a

17 Ver por ejemplo A.H.P.M. Prot: 21133; fol: 36; fecha: 20/12/75. Prot: 21133; fol: 552; fecha: $8 / 1 / 84$

18 En algunos casos, el capital en parte o en su totalidad era aportado por un agremiado que de esa manera facilitaba el establecimiento de un negocio propio a quien había estado trabajando para él. A.H.P.M. Prot: 19607; fol: 33; fecha: 1/2/79. Prot. 18925; fecha: 13/5/68. Prot: 19811; fol: 327; fecha: $11 / 6 / 88$

Hispania, LX/1, núm. 204 (2000) 225-253 
la Compañía de Comercio de Lienzos Nuestra Señora de la Salceda tras haber firmado en 1768 una obligación de pago a favor de la misma por la que se comprometía a pagar 173.967 reales en 4 años aceptando un interés anual del $3 \%$, hipotecando para ello no sólo los bienes que tenía en su casa-tienda, sino también los principales de las acciones y las utilidades que de ellas se desprendieran, así como 45.960 reales que a él le debían por el reinado de Felipe $V$ y otros 15.315 reales de otro crédito contra la Real Hacienda que le había cedido otro comerciante. En julio de 1769, Fernández Manín, Domingo González y Orduña y Manuel de Palacio Velarde, estos dos últimos como directores y administradores de la compañía, otorgaron escritura de contrata particular de sociedad y cesión respectiva de todos los géneros y efectos que tuviere en su tienda para que la compañía se biciese cobro y reintegrase la mencionada deuda en un máximo de 8 años. En dicho documento se especificaba que tanto la administración como el abastecimiento de los géneros, así como las utilidades del negocio quedarían en manos de la compañía, que nombró para que se hiciese cargo de ello a otro agtemiado a sueldo y partícipe de las ganancias. La compañía se obligaba a pagar a Manín 12 reales diarios y el alquiler del cuarto que ocupaba (lo que muy bien podía ascender a 6.500 reales anuales), siendo que una vez que se hubiera satisfecho el pago se le devolvería la tienda en el mismo estado o, en otras palabras, con el mismo valor que tenía al principio del acuerdo ${ }^{19}$.

Las condiciones incluidas en el convenio al que nos acabamos de referir no pueden considerarse traumáticas ni para los acreedores, que se aseguraban el reintegro de la totalidad de lo adeudado y no de una parte de ella como solía suceder, ni para el deudor. Este último a partir del acuerdo al que llegó con la compañía debió vivir en unas circunstancias mucho mejores que las que tuvieron que afrontar otros comerciantes no agremiados de la ciudad presionados por sus acreedores, e incluso similares a las que vivían otros miembros del sector con un volumen de capital similar al que Manín tenía invertido en su establecimiento. De hecho, en la mayor parte de las escrituras de compañía en la que se pormenorizaban las cantidades que anualmente los socios podían sacar del caudal común para satisfacer sus necesidades no solía sobrepasar los cuatro mil quinientos reales. Como mucho, pues, en este tipo de acuerdos el agremiado perdía buena parte de su capacidad para acumular, pero en contrapartida al final del período en cuestión recibía su negocio totalmente saneado.

En definitiva, todo ello debió permitir al comerciante agremiado madrileño no sólo sobreponerse a las periódicas crisis por las que pasarían sus establecimientos, sino también tener, si no todos, sí al menos una minoría, unos beneficios bastante notables (ver cuadro 5$)^{20}$.

19 A.H.P.M. Prot: 19616; fol: 161; fecha: 21/6/70

20 Las cifras incluidas en el cuadro 5 las hemos calculado operando con lo que creemos que podían ser los beneficios obtenidos por cada una de las partidas que componían los bienes de sus negocios.

Hispania, LX/1, núm. 204 (2000) 225-253 
CUADRO 5. Estimación de las utilidades anuales obtenidas por los comerciantes madrileños a finales del siglo XVIII.

\begin{tabular}{|l|l|}
\hline VALORACIÓN DE LOS NEGOCIOS & $\begin{array}{l}\text { VALORACIÓN DE LAS } \\
\text { UTILIDADES ANUALES }\end{array}$ \\
\hline Menos de 300.000 reales & Entre 5.000 y 25.000 reales \\
\hline Entre 300.001 y 1.000 .000 reales & Entre 20.000 y 70.000 reales \\
\hline Más de 1.000 .000 reales & Entre 25.000 y 300.000 reales \\
\hline
\end{tabular}

Fuente: A.H.P.M.

Comparado con lo que sabemos acerca de la situación económica de otros sectores de la sociedad madrileña, los cálculos realizados acerca de los beneficios obtenidos anualmente por los comerciantes de la capital, y entre ellos, sobre todo, acerca de los que ingresaban quienes administraban negocios valorados en más de trescientos mil reales, son sorprendentes, pues no hay que olvidar que en los mismos no se incluyen los que podían conseguir a través de las operaciones realizadas de manera coyuntural en otros sectores económicos a las que nos referiremos más adelante.

Hemos calculado que las ganancias de los agremiados debieron sobrepasar con bastante frecuencia los veinte o veinticinco mil reales, lo que suponía aproximadamente la misma cantidad que, por ejemplo, Hernández calcula en el caso de los regidores de la capital a los que dicho autor define como oligarquía madrileña ${ }^{21}$. Hay que tener presente además lo que Ringrose asegura acerca de la cuestión a la que venimos refiriéndonos, es decir que tan sólo el $1 \%$ de la población de la ciudad tenía tentas superiores a los cuarenta mil reales, mientras que sólo el $3 \%$ tenían unos ingresos anuales de entre veinte y cuarenta mil reales, cantidades que considera elevadas, pero por debajo de las que relaciona con la nobleza ${ }^{22}$. Pero, además, la notable magnitud de tales cifras se confirma si las comparamos con las de otros sectores mercantiles peninsulares. De hecho, hay que apuntat como muy probable el que los beneficios obtenidos por la mayor parte de los comerciantes madrileños superaran con frecuencia los de quienes negociaban, por ejemplo, en Valencia, al igual que lo que obtenían los cargadores a Indias asentados en Sevilla, los botiguers catalanes o los mayoristas en Santiago de Compostela o Gijón ${ }^{23}$.

21 HERNÁNDEZ (1995): 103.

22 RINGROSE (1985): 94-103. Según las cifras a las que nos hemos referido, los ingresos de los comerciantes madrileños debieron ser superiores en muchos casos a los de la nobleza asentada en otras ciudades peninsulares. Ver DONEZAR (1984): $388-410$

23 FRANCH BENAVENT (1989): 227-233. VILAR (1978): 445, afirma que si a comienzos de siglo el promedio de beneficios de una botiga se fija entre el 10 y el $11 \%$, a partir de 1750 se situaría entre el 9 y el 10\%. Por su parte, Bernal y GARCía-BAQUERO (1976): 86.88 calculan las utilida- 
Es indudable, pues, la capacidad de acumulación que tenían los comerciantes madrileños. Ante tal constatación hemos de preguntarnos por la forma en la que empleaban el capital acumulado y más concretamente si, como en otros casos de la geografía peninsular, era destinado a la compra de propiedades inmobiliarias o transferido a otros sectores económicos. Eso es precisamente lo que abordaremos en el siguiente epígrafe.

\section{LA INICIATIVA DE LOS COMERCIANTES AGREMIADOS MADRIJEÑOS EN OTROS SECTORES ECONÓMICOS.}

Hay que empezar por señalar que a través del análisis de los inventarios que elaboraron los comerciantes agremiados madrileños en el último tercio del siglo hemos podido constatar que la contabilización de propiedades inmobiliarias entre sus bienes se hace más frecuente cuanto mayor era el valor de los establecimientos que administraban. De tal manera que si entre los miembros del sector cuyas tiendas no superaban los trescientos mil reales, es decir, los de menor capacidad económica, tan sólo uno de cada diez declaraba poseerlos, uno de cada tres de entre los que tenían negocios valorados entre trescientos mil y un millón de reales manifestaban ser propietarios de bienes inmuebles, siendo que, por último, tal proporción llegaba a ser de dos de cada tres entre los más poderosos mercaderes de la ciudad ${ }^{24}$.

En el cuadro 6 se puede apreciar que la mayoría de las propiedades inmobiliarias sobre las que tenemos información no estaban valoradas en más de cincuenta mil reales. Su valor medio era de casi cincuenta y nueve mil reales, lo que supone una cifra considerable. No obstante, si excluyéramos de la muestra las que superaban los cien mil reales (una de cada cinco), probablemente nos estaríamos acercando a las dimensiones que en realidad tenían para la mayor parte de los mercaderes madrileños ${ }^{25}$. En este caso el índice medio descendería

\footnotetext{
des anuales medias obtenidas por los cargadores en algo más de seis mil reales, siendo que las tres cuartas partes de ellos no las superaban. ElRAs ROEL (1981): 521-564, cuantifica las de los mayoristas de Santiago de Compostela en algo más de diez mil reales. Cantidad muy cercana a la que BARREIRO MALION (1988): 37-53, relaciona con los de Gijón.

24 Tal tendencia a la potenciación con el enriquecimiento también se puede apreciar en otros sectores mercantiles peninsulares. Ver, por ejemplo, el caso valenciano en FRANCH BENAVENT (1989): 253-281, o el gaditano en FerNÁNDEZ MAYO (1991): 55-62. Tales comportamientos divergen de lo que otros investigadores parecen haber encontrado con respecto a comerciantes de otras plazas peninsulares, Ver por ejemplo Pérez PICAZO (1988): 121-152.

is Entre los propietarios de cierras valoradas en más de cien mil reales figuraban lógicamente algunos de los agremiados más poderosos, entre ellos hay que contar a los que se introdujeron en el comercio de lana, quienes optaron por la compra de tierras más o menos alejadas de Madrid en relación directa con sus operaciones en dicho mercado lanero. Además, integrados en el grupo minoritario at que nos venimos refiriendo estaban los escasos agremiados que al final de sus vidas dispusieron la vinculación de sus propiedades a través del establecimiento de mayorazgos: Ver, por
} 
a algo más de veintiún mil quinientos reales. Hay que tener presente, además, que, como veremos más adelante, para algunos de los comerciantes el valor total de sus posesiones era la suma de lo que suponían varias propiedades de reducido tamaño, por lo que las cifras apuntadas no reflejan claramente su importancia. Por último, es importante señalar que en relación al volumen de capital invertido en sus negocios, el que suponían sus bienes raíces no llegaba nunca a superar el diez por ciento del mismo.

CUADRO 6. Valor de las propiedades inmobiliarias de los integrantes del sector mercantil madrileño a finales del siglo XVIII.

\begin{tabular}{||l|c|}
\hline VALOR (reales) & NUMERO DE COMERCIANTES \\
\hline Menos de 1.000 & 1 \\
\hline Entre 1.001 y 5.000 & 4 \\
\hline Entre 5.001 y 15.000 & 4 \\
\hline Entre 15.001 y 30.000 & 4 \\
\hline Entre 30.00I y 50.000 & 4 \\
\hline Entre 50.001 y 100.000 & 2 \\
\hline Más de 100.001 & 5 \\
\hline Total & 24 \\
\hline \hline
\end{tabular}

Fuente: A.H.P.M.

No parece, sin embargo, que la compra de tierras o de bienes inmuebles en Madrid fuera en general consecuencia directa de una estrategia desarrollada por los comerciantes agremiados con algún fin específico. De hecho, es muy significativo que la mayor parte de las propiedades se localizaran en las regiones de donde ellos mismos procedían. Algunos incluso justificaban su posesión como consecuencia de haberlas heredado de sus familias o de las de sus esposas $^{26}$. En fin, todo ello parece confirmar que en un elevado número de ocasiones su adquisición no requirió del desembolso de cantidad alguna de dinero, ni fue consecuencia, excepto quizás en el caso de las que se derivaban de los contratos matrimoniales, de un plan predeterminado que, como sucedió en otras plazas

ejemplo, A.H.P.M. Prot: 17175 ; fol: 12; fecha: 11/1/68. Prot: 18946; fol: 193; fecha: 15/6/70. Prot: 18817; fol: 67; fecha: 16/1/80. Prot: 19824; fol: 960; fecha: 28/12/76.

26 En este caso, por la procedencia de las esposas de los comerciantes, con frecuencia las propiedades estaban situadas tanto en el norte como en las regiones del centro peninsular. Ver por ejemplo A.H.P.M. Prot: 19532; fol: 6; fecha: 20/1/68. Prot: 19109; fol: 176; fecha: 31/3/67. Prot: 18818; fol: 462; fecha: 10/11/80. Prot: 18759; fecha: $9 / 8 / 68$. 
peninsulares, tuviera como objetivo dotar a la casa comercial de una mayor estabilidad a partir de cierta diversificación en los ámbitos económicos en los que movilizaban su capital.

Tal interpretación no se contradice con lo que se ha afirmado acerca de la distribución de la propiedad entre los diferentes sectores del comercio agremiado madrileño, pues si el desempeño durante un período más o menos extenso de las actividades mercantiles en Madrid concedía la oportunidad de poder acumular cierto volumen de capital, que podía derivar en la inversión de parte de él en otros ámbitos económicos, no lo es menos el que con el paso del tiempo se produjera de forma natural la sucesión generacional y con ello la posibilidad de heredar bienes de parientes localizados en sus respectivos lugares de origen. Lógicamente, en estos casos el valor de los mismos estaba estrechamente relacionado con el poder y la significación que tenían las familias en sus respectivos contextos sociales.

Además de la importancia que tuvieron los medios de transmisión hereditarios como forma de acceso a la propiedad, como acabamos de ver, ésta también pudo derivarse indirectamente, al igual que sucedía con otros comerciantes que operaban en otras plazas españolas, del desarrollo de sus actividades, ya fueran comerciales o financieras, en otros mercados de la península, pues la mayor parte de éstas estuvieron condicionadas por la fórmula de pago aplazado y la hipoteca de bienes por parte de sus clientes como medio de asegurar los compromisos adquiridos. De esta manera llegaron a tener en sus manos tierras o casas normalmente de muy escaso valor y geográficamente muy dispersas. La mayor parte de las que así adquirían se localizaban en la región valencianomurciana y en Castilla la Nueva.

Hemos comprobado además que entre la mayoría de quienes accedían a la propiedad de bienes inmuebles situados fuera de Madrid, y sobre todo entre los que los heredaban, el interés demostrado por su explotación era muy escaso ${ }^{27}$. Es más, casi todos ellos terminaban tarde o temprano por ceder definitivamente sus derechos. Algunos lo hacían tras comprobar que su localización, casi siempre muy alejada de la capital, así como su reducido tamaño condicionaban la obtención de escasos resultados económicos de su explotación ${ }^{28}$. Otros al final de sus vidas, según quedó registrado en sus declaraciones testamentarias, entregándolas a parientes asentados en sus respectivos lugares de origen, aun-

27 A diferencia de lo que ocurría en algunos casos con las propiedades inmobialiarias localizadas en Madrid, nunca hemos llegado a enconcrar en los inventarios de bienes la contabilización de los ingresos derivados de la exploración de las que eran heredadas y situadas fuera de la capital. Ver por ejemplo A.H.P.M. Prot. 20555; fol: 368; fecha: 13/5/89

${ }_{28}$ Así lo expresaban los propios comerciantes en las escrituras en las que designaban apoderado para que procediera a su venta. Ver, por ejemplo, A.H.P.M. Prot: 22363; fol; 289; fecha: 12/6/97. Prot: 20991; fol: 341; fecha: 14/11/98. Prot. 20383; fol: 735; fecha: 29/8/84. Prot: 20426; fol: 19; fecha: 18/3/1800. Prot: 19973; fol: 159; fecha: 28/3/87. Prot: 19983; fol: 346; fecha: 30/5/97. Prot: 19983; fol: 474; fecha: 26/8/97. 
que no era extraño que éstos las hubieran estado administrando en provecho propio antes de que se protocolizara tal cesión. Esto incide sobre la importancia que llegaron a tener las estructuras familiares y su influencia sobre las relaciones sociales y económicas de los integrantes del sector agremiado del comercio madrileño a finales del siglo XVIII. En este sentido, se puede afirmar que este tipo de bienes más que un respaldo a la economía de los negocios que administraban frente a los azares de unas actividades mercantiles y financieras tan sujetas a coyunturas exteriores ${ }^{29}$, hay que considerarlo como un elemento de notable importancia en relación con la consideración social y la mejora de la situación económica de los parientes localizados en su lugar de origen y, en general, de la unidad familiar en la que se integraban los comerciantes ${ }^{30}$.

Ahora bien, a pesar de que, como venimos señalando, los comerciantes madrileños se decidieron a inmovilizar parte de su capital en la compra de propiedades con muy poca frecuencia, esto no significa que no destinaran parte del mismo a la inversión en el sector agrícola durante períodos de tiempo más cortos. De hecho, entre quienes administraban las más importantes casas mercantiles parece ser más frecuente la firma de acuerdos para el arrendamiento de explotaciones agrarias que su adquisición. En otros casos, tales operaciones podían llegar a ser una formula acordada por ambas partes para la liquidación de cuentas pendientes. Además, al igual que sucedía en otras regiones peninsulares, los comerciantes madrileños también se mostraron atraídos, aunque en menor medida de lo que lo hacían con respecto a sus propiedades, por el arrendamiento de las exacciones señoriales ${ }^{31}$.

Desgraciadamente no hemos podido conseguir información pormenorizada acerca de las cantidades que invertían en estos negocios, ni tampoco acerca de las utilidades que de ellos se derivaban, ya que entre las escrituras que contienen datos relacionados con dicha iniciativa predominan casi de manera absoluta la concesión de poderes o los compromisos de pago, en los que únicamente se hace mención al otorgante, el apoderado y a la localización de las tierras ${ }^{32}$. En la mayor parte de las ocasiones, las propiedades se ubicaban en Castilla la Vieja, Castilla la Nueva y Extremadura. En las dos primeras regiones los arten-

29 DOḾ́NGUEZ ORTIZ (1991): 201

30 Las estructuras familiares fueron esenciales a la dinámica de los negocios mercanciles de la capital. De hecho, si la mayor parte de los agremiados eran inmigrantes, las telaciones de parentesco fueron determinantes para su asentamiento en la ciudad y, más tarde, su definitiva integración al sector. De la misma manera, buena parte de ellos al final de sus vidas decidieron distribuir un porcentaje bastante considerable de lo que habían acumulado entre los parientes asentados en sus respectivos lugares de origen. SOLA CORBACHO (1998): $49-86$

31 Ver A.H.P.M. Proc. 21530; fol: 276; fecha: 28/11/88. Prot: 19795; fol: 239; fecha: 27/9/74. Prot: 18823 ; fol: 812 ; fecha: $6 / 12 / 85$

32 No obstante, hay que puntualizat que los comerciante madrileños no llegaron a invertir en estas operaciones en la misma medida que lo que lo hicieron algunos de los que negociaban en otras ciudades. Ver, por ejemplo, BerNal y GarCíA-BAQuero (1976): 94-95 
datarios solían ser miembros de la nobleza, mientras que en Extremadura aparecían con mayor frecuencia asumiendo este papel las órdenes militares ${ }^{33}$.

Por último, la concesión de créditos fue otra de las formas de canalización del capital mercantil madrileño hacia el sector agrario. De esta manera se llegaron a vincular con los sectores lanero y cerealero castellanos y de manera mucho más intensa, sobre todo entre los miembros de los gremios de sedas y de droguería, mercería y especiería, con el ámbito productivo sedero de la región valenciano-murciana ${ }^{34}$. Esta última forma de actuación se canalizó, al igual que en el caso de la lana, a través del adelanto de capital a los productores de los principales centros valencianos y sobre todo murcianos a cambio de la entrega de la parte equivalente de sus cosechas, o bien mediante el nombramiento de corresponsales a los que se encargaba de la compra y remisión de la seda levantina a la capital imperial 35 .

En definitiva, aunque no se puede pasar por alto los límites que debió imponer la escasa dinámica que caracterizaba entonces al mercado inmobiliario castellano, determinada, entre otras cosas, por la importancia que tenían tanto el mayorazgo como la amortización eclesiástica, por los datos que acabamos de aportar se puede afirmar que la gran mayoría de los comerciantes agremiados, incluidos los de mayor capacidad económica, no demostraron ningún interés por convertirse en terratenientes. Por el contrario, cuando se decidieron a intervenir en el ámbito agrario, la mayor parte de los agremiados optó por el arrendamiento o el crédito, lo que sin duda suponía no sólo la inmovilización de sus capitales durante un período de tiempo bastante más breve, sino también asumir menos riesgos.

Desde esta misma perspectiva podría interpretarse el hecho de que la mayor parte de ellos, incluidos algunos de aquellos cuyos negocios rondaban el millón de reales de principal, no sólo no se decidieran a invertir en la compra de propiedades en la capital, en un momento en el que la rentabilidad de este tipo de operaciones parece indudable ${ }^{36}$, sino que además optaran por desarrollar sus actividades mercantiles así como el resto de su vida en casas que no eran de su propiedad ${ }^{37}$, sin que su demanda de espacios habitables, por tanto,

33 Se puede encontrar información de algunos de los casos en los que los comerciantes madrileños asumieron la explotación de propiedades agrarias en A.H.P.M. Prot: 19733; fol: 114; fecha: 17/8/67. Prot: 18823; fol: 812; fecha: 6/12/85. Prot: 19795; fol: 239; fecha: 27/9/74. Prot: 21941; fol: 1; fecha: 2/1/89. Prot: 19110; fol: 138; fecha: 4/12/70. Prot. 21391; fol: 211; fecha: 3/9/92. Prot: 19810 ; fol: 96 ; fecha: $8 / 5 / 87$.

${ }_{34}$ Tal interés no ha de parecer extraño si se tiene presente la voluminosa oferta que de dicho producto se realizaba en sus establecimientos. Ver SOLA CORBACHO (1998): 49-86.

39 Ver, por ejemplo, A.H.P.M. Prot. 19117; fol: 904; fecha: 20/6/66. Prot: 19638; fol: 25; fecha: 11/3/82. Prot: 19972; fol: 268; fecha: 16/6/86. Prot; 19640; fol: 63; fecha: 19/5/87. Prot: 19793; fol: I67; fecha: 20/5/65.

36 CRUZ (1990): 239-269.

37 Esto queda puesto de relieve en numerosos inventarios realizados a la muerte de los comerciantes, ver por ejemplo A.H.P.M. Prot. 21141; fol: 148; fecha: 24/8/76. Prot. 18946; fol: 242;

Hispania, LX/1, núm. 204 (2000) 225-253 
dejara paso a la edificación de otras que pudieran convertirse en el marco físico en el que discurriera su existencia ${ }^{38}$.

Algunos investigadores han explicado su inbibición en el mercado inmobiliario urbano a partir de la existencia de cierta actitud de provisionalismo imperante en el sector mercantil madrileño en función del carácter foráneo que predominaba entre sus integrantes ${ }^{39}$. No obstante, tales afirmaciones parecen contradecirse con los deseos expresados por los comerciantes en sus propias declaraciones testamentarias acerca del lugar en donde querían que sus cuerpos fueran inhumados: la mayor parte de ellos pedían ser enterrados en Madrid ${ }^{40}$. Más trascendente nos parece también en este caso el carácter corporativo del sector y las regulaciones que condicionaban las actividades de sus miembros. De hecho, en estas últimas se incluía la delimitación de las zonas en donde los agremiados debían abrir sus establecimientos. Precisamente en ellas destacaban como los principales propietarios las oligarquías urbanas así como las instituciones eclesiásticas, y con ellos el mayorazgo y la amortización, con lo que indudablemente se frenaba la dinámica de las transacciones ${ }^{41}$. Todo ello, en definitiva, se debió demostrar en aquellas fechas como un límite prácticamente infranqueable para la iniciativa de quienes formaban parte de la corporación, mayor que en el caso que hemos expuesto en relación a la propiedad de tierras en el ámbito agrario.

Por todo lo que acabamos de señalar así como por lo que apuntamos acerca del volumen de capital que invertían en la compra de acciones de las compañías gremiales y por lo que sabemos acerca de las actividades de estas últimas, es bastante probable que por término medio fueran más elevadas las transferencias realizadas por el comercio agremiado madrileño al sector manufacturero que a la compra de propiedades, ya fueran rurales o urbanas, a la contratación de asientos con la administración real o municipal o que las inversiones realiza-

fecha: 22/1/76. Prot: 21086; fol: 819; fecha: 3/10/92. Prot: 21094 ; fol: 57; fecha: 31/1/1800. Prot. 19973; fol: 273; fecha: 29/4/87. Prot: 19892; fol: 224; fecha: 22/12/79

${ }_{38}$ El dinero que invertían en hacer habitables sus casas tampoco era demasiado importante. Si a ello le sumamos el que destinaban a la compra de ropas y vesridos tenemos que entre los comerciantes cuyos negocios no sobrepasaban los trescientos mil reales representaban algo más del ocho por ciento del total de sus bienes, entre los que administraban un establecimiento de más de trescientos mil reales y menos de un millón suponía casi el cinco por ciento, mientras que entre los más ticos descendía a menos del dos por ciento.

39 RINGROSE (1986): 301-323

to En las 223 declaraciones testamentarias que hemos podido localizat, menos de la cuarta parte de los comerciantes dejaban la decisión sobre la elección del lugar en donde reposarían sus cuerpos tras la muerte a sus albaceas o apoderados. Todos los demás quisieron ser enterrados en el recinto eclesiástico del que eran parroquianos, excepto una quinta parte que deseaba que la inhumación se realizara en alguno de los conventos de órdenes regulares situados en Madrid, mientras que sólo uno quiso ser inhumado fuera de la ciudad.

41 CRUZ (1990): 239-269. HERNÁNDEZ (1995): 148 
das en el sector agrario. Es por eso que queremos finalizar este trabajo refiriéndonos a su iniciativa en el ámbito de las manufacturas.

Como ya señalamos, tal iniciativa fue desarrollada por alguno de los cinco gremios de manera individual al establecer sus propios centros de producción. Entre ellos se podrían incluir, por ejemplo, la fábrica de listonería y cintería de Valdemoro, establecida por la Compañía de Lonjistas en 1785, o la de holandillas, fundada por el Gremio de Droguería, Mercería y Especiería a comienzos de la centuria y que en los primeros años de la década de los ochenta pasó a manos de la Compañía General de los Cinco Gremios Mayores de Madrid. Sin embargo, hay que precisar que de manera mayoritaria tales actividades relacionaban a la corporación con las fábricas cuyo origen o historia estaban vinculadas a la iniciativa o protección real. Capella y Matilla Tascón en su trabajo acerca de los Cinco Gremios Mayores se refieren a la responsabilidad que sucesivamente fueron adquiriendo desde 1752 en la administración de la fábrica de tejidos de seda, plata y oro de Valencia, las reales fábricas de Guadalajara, Brihuega y San Fernando, la fábrica de tejidos de seda, plata y oro de Talavera, la fábrica de paños de Ezcaray, la fábrica de tejidos de lana de Cuenca, la fábrica de hilar y torcer seda a la piamontesa de Murcia y la fábrica de sombreros de San Fernando ${ }^{42}$.

En el marco de la política de fomento de las manufacturas que desde prácticamente su llegada al trono impulsaron los Borbones, es muy probable que lo que buscaran las autoridades al arrendar las reales fábricas a los Cinco Gremios Mayores de Madrid más que reducir los costes que su explotación suponía para la Real Hacienda, como algunos investigadores han venido señalando ${ }^{43}$, fuera la potenciación de la producción nacional como freno a las importaciones de productos extranjeros ${ }^{44}$. Es posible además que influyeran otros aspectos en el desarrollo de esta estrategia por parte de los gobernantes; entre ellos habría que tener en cuenta, como señala González Enciso, el mayor peso específico

42 Capella y Matilla Tascón (1957): 133-180. Ver también Helguera Quijada (1996): 115-140 y GONZȦLEZ MUÑOZ (1973): 629-660. GONZÁLEZ ENCISO (1980): 160

43 Ver Helguera QuijadA (1991): 51-87 y Helguera Quijada (1996): 115-140, ANes (1989): 1-138. FERNÁNDEZ DIAZ (1985): 16-53.

44 Por lo que se desprende de GonZÁleZ ENCISO (1994): 75-99, los resultados obtenidos de la explotación de la Real Fábrica de Guadalajara no fueron muy alentadores durante la primera mitad del siglo. Sin embargo, hay datos que apuntan a que la mejora en los rendimientos pudo llegar a ser progresiva a lo largo de la segunda mitad de la centuria. De hecho, si entre 1783 y 1790 el gasco de la Real Hacienda, según GONZÁLEZ ENCISO (1988): 69-98, fue de 1.786 millones de reales, el coste asociado al mantenimiento de la Real Fábrica de Paños de Guadalajara suponía el $5 \%$ de dicha cantidad, o lo que es lo mismo, algo más de un millón de reales anuales, CuENCA ESTEBAN (1981): 183208, calcula que para el quinquenio 1788-1792 la media aritmética anual de los ingresos procedentes de la citada fábrica ascendió a más de un millón seiscientos mil teales, por lo que hay que considerar la posibilidad de que para entonces de la explocación de la fábrica se obcuvieran utilidades. 
que fue adquiriendo conforme avanzaba el siglo, aunque tal trayectoria se frustrara en definitiva, las ideas liberales ${ }^{45}$.

En lo que respecta a la aceptación de las propuestas realizadas por los Cinco Gremios Mayores para su administración, es muy probable que influyera de manera favorable la posición que la corporación ocupaba en el mercado madrileño y lo que esto significaba para poder satisfacer al menos uno de los objetivos de la política en la que se enmarcó el esfuerzo de los gobernantes: la sustitución de importaciones en una de las plazas más importantes del territorio peninsular. De hecho, como se puede apreciar en el cuadro 7, el resultado del análisis que hemos realizado sobre los inventarios de los establecimientos propiedad de los comerciantes agremiados y, más concretamente, de las mercadurías ofertadas en los mismos y su procedencia, parece constatar el éxito de la mencionada estrategia a lo largo de los últimos treinta y cinco años de la centuria ${ }^{46}$.

A partir de tales datos se puede afirmar que los comerciantes de Madrid a finales del siglo XVIII estaban satisfaciendo las necesidades de la ciudad mediante la importación de textiles elaborados mayoritariamente en España. Entre ellos destacaban los paños procedentes de las Reales Fábricas de San Fernando, Guadalajara, Brihuega, Alcoy y Ezcaray, así como los que llegaban de Cuenca, Teruel, Onteniente, la Rioja, Ajofrín y Segovia, y los que se importaban de Cataluña ${ }^{47}$, los tejidos de seda de Valencia, Requena, Talavera de la Reina, Toledo, Barcelona y de la denominada Nueva Fábrica situada en Madrid $^{48}$, y la seda en bruto valenciana o murciana ${ }^{49}$, los derivados del lino galle$\mathrm{go}^{50}$, los sombreros fabricados en la Real Fábrica de Sombreros de San Fernando y en menor medida en Barcelona, León o en algunas localidades de Galicia o, por último, los hilos elaborados en la mencionada región, así como en Córdoba o León. En definitiva, todo ello parece confirmar que Madrid estaba estrechamente vinculada con algunos de los más importantes centros de producción peninsulares, fundamentalmente con aquellos que estaban directamente relacionados con la iniciativa de la Corona, es decir, las reales fábricas, y en menor medida con los que estaban administrados por la iniciativa privada.

45 GONZÁLEZ ENCISO (1980): 237-255

$46 \mathrm{Al}$ no haber encontrado ningún inventario no se han podido incluir los datos relacionados con las ziendas de los miembros del Gremio de Drogueria, Especiería y Merceria que se especializaron en la distribución de especias y géneros medicinales.

47 La producción de paños catalana procedía de la zona en la que TorRas (1984): 113-127, localiza la producción de tejidos de calidad media y alca, es decir, Tarrasa, Barcelona, Reus e Igualada.

48 Entre los tejidos de seda destacaban los tafetanes, rasos y moeres. En menor medida hemos encontrado cortes de vestido, medias, hermosillas, tapices, pañuelos y guantes

49 Entre los productos puestos a la venta por los comerciantes del Gremio de Droguería, Especiería y Mercería la seda procedente de Valencia y Murcia y el hilo cordobés, leonés o gallego suponían el $40 \%$ del total de mercancías ofertadas y casi las dos terceras partes de los géneros de origen español.

so Fundamentalmente lienzos caseros (viveros, coruñas, santiagos y lorenzanas) 
CUADRO 7. Procedencia de las mercancías ofertadas por los comerciantes agremiados madrileños a finales del siglo XVIII (en porcentajes)

\begin{tabular}{|l|c|}
\hline PROCEDENCIA & TOTAL \\
\hline España & 60 \\
\hline Confuso & 16 \\
\hline Francia & 14 \\
\hline Inglaterra & 4 \\
\hline Países Bajos & 3 \\
\hline Alemania & 2 \\
\hline Italia & 1 \\
\hline Portuga! & 0 \\
\hline TOTAL & 100 \\
\hline
\end{tabular}

Fuente: A.H.P.M.

Desde la perspectiva gremial hay que plantearse si su intervención se vio condicionada por intereses estrictamente económicos o si bien fue una maniobra que de manera indirecta estaba orientada a asegurar los privilegios que la Corona había concedido a la corporación tiempo atrás en otros sectores de la economía, sobre todo en los que se relacionaron con el mercado de la capital, a cambio de un cierto coste económico que, en cualquier caso, y como consecuencia de la participación de los agremiados a través de la adquisición de acciones, se repartiría entre cada uno de sus miembros.

En principio, es indudable que la política borbónica proteccionista y de fomento de la producción y circulación de las manufacturas españolas en los mercados peninsulares, pudo significarse de manera muy favorable en el interés estrictamente económico de la institución por involucrarse en el ámbito al que venimos refiriéndonos. En este sentido, hay que destacar las facilidades concedidas por las autoridades respecto a las empresas protegidas en lo que hace a los procesos de producción, a la calidad de los textiles ${ }^{51}$ o a la reducción de los de-

31 Por ejemplo, en relación a la fábrica valenciana, no sólo consiguieron derechos de tanteo en la adquisición de materias ptimas para la producción, sino que incluso se les permitió variar las características de los productos a los que dotaron de una ley y peso inferiores a los reglamentarios. Cuando los Cinco Gremios Mayores de Madrid se hicieron cargo de la Real Fábrica de Ezcaray, consiguieron de las autoridades franquicias a la importación de los materiales necesarios para la producción tratando de conseguir la prohibición de establecimiento de cualquier otra fábrica en las cercanías para así monopolizar la mano de obra. Infotmación sobre los privilegios concedidos en otros casos se pueden encontrar en Thomson (1995): 74-110. ENCISO Recio (1963), CARRERA PUJAL (1947)

Hispania, LX/1, núm. 204 (2000) 225-253 
rechos asociados a la comercialización de su producción fundamental pero no únicamente en contra de los géneros franceses e ingleses ${ }^{52}$.

Por si ello no fuera suficiente para dotar del atractivo suficiente a la inversión, la propia estructura de la corporación y fundamentalmente las relaciones definidas entre el comerciante, su gremio y las compañías creadas en su seno aseguraban el interés por el negocio, ya que de esa manera y al mismo tiempo se podía conseguir la satisfacción de las necesidades de abastecimiento de las tiendas de los agremiados y la apertura de un camino para la distribución de las mercadurías producidas en los citados establecimientos, por lo que, si los comerciantes reducían gastos al obtener las mercancías directamente del productor (la corporación), otro tanto se puede afirmar con respecto a las fábricas al disminuir así los costes de comercialización.

Todo ello, en definitiva, nos permite reafirmarnos en la idea de la existencia de importantes intereses económicos como transfondo de las negociaciones que culminarían en la firma de los acuerdos para el arrendamiento de las reales fábricas no sólo en el caso de la Corona, sino también en el de los Cinco Gremios Mayores de Madrid. Por una parte, como ya hemos visto, porque los gobernantes podían valerse de ellos para impulsar, en consonancia con su politica de fomento de las manufacturas nacionales, la comercialización de manufacturas elaboradas en España. Por otra, porque el comercio agremiado de Madrid encontraba en ello, como ya hemos señalado, una doble fórmula para rentabilizar la inversión realizada, ya que de esa manera, en primer lugat, conseguía reducir los costes de abastecimiento de su comercio y aumentar sus posibilidades de conseguir utilidades en los mercados en los que intervenías3, y, en segundo lugar, porque al contribuir a la distribución de los productos del establecimiento administrado por la compañía de la que era accionista estaba ayudando a rentabilizar la iniciativa institucional.

\section{CONCLUSIONES}

A lo largo del presente trabajo hemos presentado algunos de los rasgos más notables que caracterizaron la dinámica de los negocios de los comerciantes matriculados como miembros de los Cinco Gremios Mayores de Madrid. Entre ellos hay que destacar no sólo el importante volumen de capital que en ellos

52 RODRíGUEZ LABANDEIRA (1982): 107-184, señala que junto a tales medidas, por Real Cédula de 1779 , se imponía sobre la entrada de paños extranjeros el pago de entre el 10 y el $14 \%$ de sts valor.

53 Hemos podido comprobar por el elevado número de apoderados que nombraron para que les representaran fuera de la capital que los agremiados en el último tercio del siglo desarrollaron parte de sus actividades comerciales y financieras fuera de Madrid. Las plazas en las que con mayor frecuencia intervenían se encontraban prioritariamente en Castilla la Vieja, Castilla la Nueva, Andalucía y Valencia-Murcia. Ver SOLA CORBACHO (1998): 196-225

Hispania, LX/1, núm. 204 (2000) 225-253 
tenían invertido o los notables resultados que podían obtener anualmente de los mismos, sino también que los medios de los que se valieron para que así fuera distan bastante de los que la historiografía tradicionalmente había venido definiendo. En este sentido hay que confirmar lo que apuntábamos en un principio, esto es, que hay que diferenciar entre la iniciativa de cada uno de los agremiados de manera individual en el marco de su establecimiento mercantil y las que emprendieron de manera conjunta agrupados en la Diputación o en las compañías creadas a lo largo de la centuria. De hecho, como hemos podido comprobar, tan sólo alrededor de una séptima parte de sus caudales estaba siendo negociado a través de las instituciones corporativas.

En lo que hace a la iniciativa individual, ya hemos visto que, independientemente del nivel de capitalización de sus establecimientos, la mayor parte del caudal con el que contaban los comerciantes madrileños se orientó prioritariamente hacia su inversión en el ámbito financiero-mercantil, satisfaciendo las necesidades de la población de la capital imperial, así como las de otras plazas del interior peninsular. Esto, como ya hemos podido comprobar, significa que ni los comerciantes madrileños destinaron parte de sus ganancias a procurarse una vida lujosa, no hay que olvidar el escaso valor que tenían sus propiedades personales, ni se vieron atraídos por la compra de bienes inmuebles, pues, como ya señalamos, la mayor parte de ellos ni siquiera eran propietarios de la casa que habitaban y en la que se desarrollaban sus negocios.

En lo que hace a la dinámica impulsada en el marco de la corporación, según los datos de los que disponemos, fueron más los comerciantes que tenían intereses en alguna de las compañías creadas por los gremios durante la segunda mitad del siglo que los que se decidieron a invertir parte de sus caudales en otras instituciones corporativas. Teniendo presente lo que hemos señalado acerca de las actividades de las citadas compañías, se puede afirmar que la mayor parte del capital con el que negociaron institucionalmente, al menos durante los últimos treinta y cinco años de la centuria, fue movilizado hacia el ámbito financiero, comercial o manufacturero. Esto, como ya dijimos, les permitió entrar en contacto directo con el ámbito productivo español, a través fundamentalmente del arrendamiento de algunas de las reales fábricas, lo que, además, propició que tanto a nivel individual como colectivamente fuera bastante notable la importancia que tuvieron los géneros elaborados en España entre los que eran comercializados por el sector.

De la misma manera, tales vínculos y las relaciones que existían entre los agremiados y las compañías de comercio no sólo debieron condicionar el que no se estableciera una relación de dependencia y jerarquización en el interior del grupo en función de la capacidad de los negocios, sino que además debió fortalecer su privilegiada situación en el mercado de la capital y su competitividad en otras plazas del interior peninsular. Desde esta última perspectiva, se puede afirmar por tanto que los miembros de los Cinco Gremios Mayores de Madrid se estaban encargando de que en el más importante mercado peninsu- 
lar se consumieran fundamentalmente textiles españoles, pero también de distribuirlos fuera de la capital, convirtiéndola así en un centro redistribuidor de géneros nacionales.

Evidentemente si la actuación del comercio agremiado madrileño pudo llegar a ser tan diferente a la que hasta ahora se ha venido afirmando, hay que preguntarse por las razones que condicionaron el que incluso así los efectos sobre el sistema económico español fueran los mismos que los que se han venido describiendo tradicionalmente en las circunstancias antes apuntadas. En otras palabras, habría que saber por qué de su intervención en el ámbito de las manufacturas y en el de los mercados interiores no se derivaron progresos sustanciales en el mencionado sector y en la articulación de los espacios comerciales del interior peninsular.

En lo que hace a la primera de las dos cuestiones, hay que reconocer que la intervención de los Cinco Gremios Mayores en el sector manufacturero pudo ayudar al éxito de la política proteccionista borbónica, como pudimos comprobar al analizar las mercadurías puestas a la venta en las tiendas de los agremiados, $e$ incluso que al comprometerse en la movilización de los productos elaborados en las reales fábricas hacia el principal mercado español, estuvieran contribuyendo a la relativa estabilidad de la que gozaron dichos centros de producción al menos en las últimas décadas de la centuria. Ahora bien, de la misma manera, hay que subrayar que si los resultados de la iniciativa emprendida por la corporación y de las medidas implantadas por los reformistas pudieron liegar a satisfacer las expectativas de unos y otros, por el contrario, las consecuencias que de ellas se desprendieron para las economías del interior peninsular, y sobre todo para sus manufacturas, no fueron ni mucho menos tan positivas. Así, se puede afirmar que tanto los privilegios concedidos por las autoridades como la capacidad de la corporación pudieron propiciar la introducción de importantes factores de distorsión no sólo en los mercados de materias primas sino también en los de elaborados a favor de los establecimientos administrados por los gremios, pues en ambos casos competian en condiciones muy ventajosas respecto a los pequeños centros manufactureros que habían destacado tradicionalmente en el mencionado contexto regional, llegando a convertirse en un factor determinante de la progresiva decadencia que vivieron estos últimos a lo largo de la centuria, sin que las tardías medidas gubernamentales que generalizaron tales privilegios pudieran frenarla ${ }^{54}$. Pero además, es necesario puntualizar que las ventajas así conseguidas, no sólo respecto al resto de la producción nacional, sino también en relación a las mercancías elaboradas en otros enclaves europeos, debieron influir decisivamente sobre la propia evolución de los establecimientos a los que nos venimos refiriendo, ya que evidentemente no se veían condicio-

34 GonZÁlez ENCISO (1983): 147-170, confirma tal afirmación en el caso de los centros de profucción rutal del norte de Castilla desde mediados de la centuria, aunque lo relaciona únicamente con la ineficacia de las mencionadas medidas proteccionistas.

Hispania, LX/1, núm. 204 (2000) 225-253 
nados a mejorar sus sistemas de producción al definir su competitividad en términos políticos y mercantiles.

Si nos preguntamos por las razones que determinaron que la intervención del comercio agremiado madrileño en otras plazas peninsulares no generaran cambios en la articulación espacial de las regiones en las que éstas se integraban, es evidentemente que hemos de hacer lo mismo con respecto a las formas en que lo hicieron. En este sentido, hay que volver a insistir en que su iniciativa no introdujo cambios sustanciales que modificaran los tradicionales vínculos mercantiles existentes en el interior peninsular, sino que más bien debieron aprovecharse de los existentes, reforzando de esa manera la importancia de los circuitos feriales, sin que ello diera paso, por tanto, a la implantación de una red estable y jerarquizada de distribución articulada en torno a la capital imperial. Precisamente, entendemos que en el propio sistema así configurado es donde se encuentran los límites a la dinámica a la que venimos refiriéndonos. De hecho, de tal definición se desprende el carácter coyuntural del proceso, pues si bien las circunstancias facilitaron la intervención del comercio madrileño, de ello no se derivaron cambios estructurales trascendentales en la organización de las regiones del interior que pudieran haber sido utilizadas eficientemente en momentos posteriores.

Pero, además, si fueron dichos canales los que utilizaron para introducirse en el ámbito financiero y comercial del interior peninsular, es más que probable que en lugar de apoyarse en los sectores comerciales regionales para desarrollar sus actividades en los mercados en los que éstos negociaban, su iniciativa conllevara la competencia con los mismos. En estas circunstancias, la desproporcionada capacidad de los agremiados madrileños con respecto a cualquier otro núcleo mercantil de dichos territorios, basada en la estructura corporativa sobre la que descansaba su dinámica y, más concretamente en este caso, en la especial relación que a través de las instituciones creadas en el seno de la corporación mantenían con respecto a algunos de los principales centros de producción peninsulares, debió convertirse en un potencial desestabilizador de las tradicionales relaciones mantenidas entre los núcleos de población localizados en dichas regiones, pues su introducción en el circuito ferial debió significar la satisfacción de las necesidades tanto de los más importantes centros de población como de los más pequeños asentamientos de dichas regiones del interior.

Todo ello hace que se pueda entender que, en general, a la pérdida de influencia de los principales núcleos de población del interior peninsular, y fundamentalmente de los que formaban parte de Castilla la Vieja y Castilla la Nueva, en relación a su funcionalidad como centros manufactureros, comerciales y financieros con respecto a los territorios incluidos en la mencionada región y con ello la progresiva desarticulación espacial registrada en el siglo XVII, sucedió cien años más tarde la aparición de unas circunstancias propicias a la recuperación en este sentido y que no fueron aprovechadas no sólo por los límites que imponía la introducción de productos procedentes de otras regiones, 
sino también por la dinámica de las casas de comercio madrileñas que se encargaron en buena medida de su distribución. Se podría afirmar, pues, que las nuevas condiciones surgidas fueron utilizadas por el sector mercantil de Madrid que, de esta manera, impedía una ordenación equilibrada del espacio castellano aportando elementos que progresivamente fomentaban la centralización en torno a la capital imperial.

\section{BIBLIOGRAFÍA}

ALMANAK MERCANTIL • Guía de Comerciantes. (1796). Madrid. Imprenta de Ramón Ruiz.

ANES, Gonzalo (1989). «Sociedad y economía». Actas del Congreso Internacional sobre «Carlos III y la llustraciónx. Madrid. Ministerio de Cultura. Vol II, p. 1-138.

BARREIRO MALlon, Baudilio (1988), «Agricultura e industria en la Asturias en el siglo XVIII". La industrialización del norte de España. E. Fernández de Pinedo y J.L. Hernández Marco (ed). Barcelona. Crítica, p. 37-53.

BERNAL, Antonio Miguel y GARCÍA-BAQUERo, Antonio (1976). Tres siglos de comercio sevillano (1598-1868). Sevilla. Cámara Oficial de Comercio, Industria y Navegación de Sevilla.

Capella, Miguel y Matilla Tascón, Antonio (1957). Los Cinco Gremios Mayores de Madrid. Estudio crítico bistórico. Madrid. Cámara de Comercio de Madrid.

CARRERA PUjAL, J. (1947) Historia política y económica de Cataluña. Barcelona.

CruZ, Jesús (1990). «Propiedad urbana y sociedad en Madrid». Revista de Historia Económica, 2, p. 239-269.

CuenCa Esteban, Javier (1981). «Ingresos netos del Estado español». Hacienda Pública Española, 27, p. 183-208.

DOMÍNGUEZ ORTIZ, Antoni (1991). «Los comerciantes en la sociedad andaluza de la llustración». La burguesía de negocios en la Andalucia de la llustración. A. García-Baquero (ed.). Cádiz. Diputación General de Cádiz. Tomo I, p. 193-206.

DONEZAR, Javier María (1984). Riqueza y propiedad en la Castilla del Antiguo Régimen. La provincia de Toledo en el siglo XVIII. Madrid. Instituto de Estudios Agratios, Pesquetos y Alimentarios.

EIRÁs ROEL, Antonio (1981). «La burguesía mercantil compostelana a mediados del siglo XVIII: mentalidad tradicional e inmovilismo económicom. La bistoria social de Galicia en sus fuentes de protocolos. A. Eirás (ed). Santiago de Compostela. Universidad de Santiago de Compostela, p. 521-564.

ENCISO RECIO, Luis Miguel (1963). Los establecimientos industriales españoles en el siglo XVIII. La mantelería de la Coruña. Madrid. Rialp.

FERNÁNDEZ, Roberto (1982). «La burguesía barcelonesa en el siglo XVIII: la familia Gloria». La economía española al final del Antiguo Régimen. P. Tedde (ed). Madrid. Alianza. Vol II p. 1-131.

FERNÁNDEZ DíAZ, Roberto. (1985). «España en el siglo XVIII o los límites de una reforma». España en el siglo XVIII. Homenaje a Pierre Villar. R. Fernández (ed) Barcelona. Crítica p. 16-53.

FERNÁNDEZ MAYO, Manuela (1991). «La propiedad urbana en Cádiz a mediados del siglo XVIII: pautas del comportamiento de la burguesía mercantil». La burguesía de negocios

Hispania, LX/1, nim. 204 (2000) 225-253 
en la Andalucía de la llustración. A. García-Baquero (ed). Cádiz. Diputación General de Cádiz.

FRANCH BENAVENT, Ricardo (1989). El capital comercial valenciano en el siglo XVIII. Valencia. Universidad de Valencia.

GoNZÁLEZ ENCISO, Agustín.(1980). Estado e industria en el siglo XVIII: la fábrica de Guadalajara. Madrid. Fundación Universitaria Española.

- (1983). «La industria lanera en la provincia de Soria en el siglo XVIII». Cuadernos de Investigación Histórica, 7, p. 147-170.

- (1988). «La industria de la lana en el siglo XVIII».La economía de la Ilustración. Murcia, p. 69-98.

- (1994). «Inversión pública e industria textil en el siglo XVIII. La Real Fábrica de Guadalajara. Notas para su estudion. Lecturas de Historia Empresarial. J. Hernández y J.L. García (ed). Madrid, p. 75-99.

González MuÑoz, María del Carmen (1973). «La Real fábrica de Sedas de Talavera de la Reina (1748-1851". Hispania, 125, p. 629-660.

Helguera QUIJADA, Juan. (1991). «Las Reales Fábricas». Historia de la empresa pública en España. F. Comín y P. Martín Aceña (dir). Madrid. Espasa Calpe. p. 51-87.

- (1996). «Empresas y empresarios manufactureros en la España del siglo XVIII». La empresa en la bistoria de España. F. Comín y P. Martín Aceña (eds). Madrid. Civitas, p. 115-140.

HeRnández, Mauro (1995). A la sombra de la Corona. Pader local y oligarquía urbana (1606-1808). Madrid. Siglo XXI.

LARRUGa, Eugenio. (1787). Memorias politicas y economicas sobre los frutos, comercio, fábricas $y$ minas de España. Madrid. Imprenta de Benito Cano.

PÉrez PICAZo, María Teresa (1988). «El comercio murciano en la segunda mitad del siglo XVIII". La economía de la Ilustración. Cuademos del Seminario Floridablanca, 2, Murcia, p. 121-152.

Ringrose, David R. (1985). Madrid y La economía española, 1560-1850. Madrid. Alianza.

- (1986). «Ciudad, país y revolución burguesa: Madrid, del siglo XVIII al siglo XIX». Madrid en la sociedad del siglo XIX. La ciudad y su entorno. Madrid, centro de poder politico. Poder económico y elites locales. Madrid. CIDUR, Vol I, p. 301-323.

RODRígueZ LABANDEIRA, José. (1982). «La política económica de los Borbones». La economía española al final del Antiguo Régimen. Madrid. Alianza/Banco de España. Vol .IV p. 107-184.

Sola Corbacho, Juan Carlos (1998). Las ciudades de Madrid y México ante la independencia. Tesis doctoral inédita.

THOMSON, J.K.J. (1995). "Intervención del Estado en la industria catalana de estampado de telas en el siglo XVIII». Mercados y manufacturas en Europa. M. Berg (ed). Barcelona. Crítica, p. 74-110.

TORRAS ELÍAS, Jaume. (1984). «Especialización agricola e industria rural en Cataluña en el siglo XVIII", Revista de Historia Económica 3, p. 113-127.

VILAR, P. (1978). Cataluña en la España moderna. Barcelona. Crítica 